\title{
Sistem Pendukung Keputusan dengan Metode Simple Additve Weighting (SAW) untuk Prediksi Anggaran Biaya Wisata
}

\author{
Yhogi Andianggara ${ }^{1}$, Rohmat Gunawan ${ }^{2}$, Aldy Putra Aldya ${ }^{3}$ \\ ${ }^{1,2,3}$ Porogram Studi Informatika Universitas Siliwangi \\ 'yhogi@gmail.com, rrohmatgunawan@unsil.ac.id, ${ }^{3}$ aldy@unsil.ac.id
}

\section{INFORMASI ARTIKEL}

Sejarah Artikel:

Diterima Redaksi:

Revisi Akhir:

Diterbitkan Online:

\begin{tabular}{l} 
KATA KUNCI \\
\hline Anggaran \\
Prediksi \\
SPK \\
SAW \\
Wisata \\
KORESPONDENSI \\
\hline
\end{tabular}

Telepon: +62323151100

E-mail: rohmatgunawan@unsil.ac.id

\begin{abstract}
A B S T R A K
Memprediksi anggaran perencanaan biaya wisata merupakan salah satu aktivitas yang harus dilakukan sebelum melakukan perjalanan wisata, sehingga kegiatan perjalanan wisata tidak mempengaruhi stabilitas keuangan dan anggaran tersebut dapat digunakan sebagai referensi untuk melakukan tour berikutnya. Pembuatan prediksi anggaran biaya perjalanan wisata tidak mudah dilakukan dan membutuhkan pertimbangan beberapa faktor, serta melibatkan proses perhitungan. Agar prediksi akurat dari anggaran biaya perjalanan wisata dapat dilakukan, diusulkan untuk menerapkan sistem pendukung keputusan menggunakan metode Simple Additive Weighting (SAW). Algoritma SAW digunakan dalam penelitian ini karena dapat memberikan alternatif prediksi anggaran perjalanan terbaik berdasarkan peringkat informasi anggaran yang ada. Hasil percobaan pada penelitian menunjukkan bahwa, penerapan metode SAW dengan menggunakan 3 parameter (total biaya anggaran, lama liburan, jumlah orang) serta proses penyaringan (filterisasi) pada data anggaran yang telah tersimpan berdasarkan parameter tujuan objek wisata, dapat memberikan alternatif prediksi anggaran perjalanan wisata terbaik.
\end{abstract}

\section{PENDAHULUAN}

Sektor pariwisata nasional kini menjadi primadona baru bagi pembangunan nasional. Sumbangan devisa maupun penyerapan tenaga kerja dalam sektor ini amat signifikan bagi devisa negara. Pada 2015, devisa dari sektor pariwisata sebesar US\$ 12,225 miliar dan pada tahun 2016 devisa dari sektor pariwisata sebesar US\$ 13,568 miliar. Sektor pariwisata menjadi penyumbang devisa negara terbesar kedua pada tahun 2016 dan akan terjadi peningkatan pemasukan devisa dari sektor pariwisata. Diperkirakan pada tahun 2019, sektor pariwisata menjadi penyumbang utama devisa utama Indonesia [1].

Membuat prediksi rencana anggaran biaya wisata merupakan salah satu hal yang harus dilakukan agar aktivitas liburan tidak mempengaruhi kestabilan finansial setelah pulang berlibur [13]. Prediksi anggaran biaya wisata yang akurat dapat dijadikan acuan untuk menentukan anggaran wisata selanjutnya. Tahap pembuatan prediksi anggaran biaya merupakan hal yang tidak mudah dilakukan dan berhubungan dengan perhitungan yang melibatkan beberapa parameter.

Beberapa penelitan tentang prediksi biaya telah dilakukan sebelumnya, diantaranya menggunakan metode Fuzzy [9], 17], Simple Additive Weighting (SAW) [2], [4], Tverski [5], Profile Matching [8] dan CBR [3], [7], [15]. Pada penelitian [9], metode fuzzy digunakan untuk menyelesaikan masalah prediksi harga jual sepeda motor bekas, dengan menggunakan parameter: kondisi sepeda motor, jarak tempuh sepeda motor, pajak STNK sepeda motor, tahun pembuatan atau perakitan motor yang tertera dalam BPKB dan STNK, dan warna sepeda motor. Hasil percobaan pada penelitian diperoleh prediksi harga jual sepeda motor bekas.

Pada penelitian [2], metode SAW digunakan untuk menyelesaikan masalah pemilihan mahasiswa berprestasi dengan paramter: IPK, karya tulis ilmiah, prestasi atau kemampuan yang diunggulkan dan bahasa inggris/asing, 
sehingga diperoleh informasi pendukung keputusan pemilihan mahasiswa berprestasi yang akurat sesuai dengan ketentuan. Pada penelitian [4], metode SAW digunakan untuk menyelesaikan masalah penentuan biaya Sumbangan Penyelenggaraan Pendidikan (SPP) bagi siswa baru, dengan parameter: jurusan, jumlah penghasilan orang tua, jumlah tanggungan orang tua, pekerjaan orang tua dan wawancara, sehingga diperoleh penentuan biaya SPP yang bersifat akurat dan tepat waktu.

Pada penelitian [5], metode Tverski digunakan untuk menyelesaikan masalah penentuan harga rumah dengan parameter: lokasi rumah, luas, kualitas bangunan, fasilitas rumah, akses transportasi dan sertifikat, sehingga diperoleh penentuan harga rumah dengan tingkat keberhasilan $70 \%$. Pada penelitian [8], metode Profile Matching digunakan untuk meyelesaikan masalah pemilihan objek wisata dengan parameter: biaya wisata, fasilitas, jenis objek wisata dan jarak tempuh, sehingga diperoleh perbandingan antara kompetensi pengunjung kedalam kompetensi objek wisata. Pada penelitian [15], metode Case-Based Reasoning (CBR) digunakan untuk menyelesaikan masalah penentuan kelompok Uang Kuliah Tunggal (UKT) dengan parameter: pendidikan, pekerjaan, usia kepala keluarga, tanggungan, pendapatan dan aset, dengan metode pengukuran similaritas yang digunakan yaitu Nearest Neighbor $(N N)$ sehingga diperoleh kemiripan kasus baru terhadap kasus lama yang dijadikan bahan pertimbangan untuk menentukan kelompok UKT.

Metode Simple Additive Weighting (SAW) dikenal dengan metode penjumlahan terbobot [6]. Metode SAW dilakukan dengan mencari penjumlahan bobot dari rating kinerja pada setiap alternatif pada semua atribut, sehingga dapat menentukan alternatif terbaik. Agar diperoleh prediksi anggaran biaya wisata dengan alternatif terbaik, maka pada penelitian ini diterapkan metode Simple Additive Weighting (SAW) dengan mengambil 3 kriteria sebagai atribut untuk proses pengolahan data yaitu : total biaya wisata, lama liburan dan total jumlah orang. Pada penelitian ini akan diambil 5 data anggaran biaya wisata sebelumnya, yang telah tersimpan pada sistem, untuk dijadikan bahan perhitungan alternatif yang akan direkomendasikan untuk dijadikan prediksi anggaran biaya wisata yang akan dibuat saat ini.

\section{METODOLOGI}

Terdapat empat tahap yang dilakukan pada penelitian ini yaitu: Analisis, Perhitungan Prediksi dengan Metode SAW, Perangcangan Sistem, Implementasi dan Pengujian seperti ditampilkan pada Gambar 1.

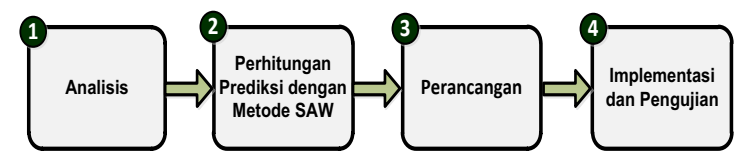

Gambar 1. Tahapan Penelitian

\subsection{Analisis}

Tahap ini dilakukan untuk mengetahui faktor-faktor yang berhubungan dengan perhitungan anggaran biaya wisata. Berdasarkan hasil analisis diperoleh 3 parameter yang berhubungan dengan perhitungan anggaran biaya, yaitu: total biaya wisata, lama liburan dan jumlah orang. Penerapan metode SAW pada perhitungan anggaran biaya wisata, akan mengacu pada informasi data anggaran wisata yang sebelumnya. Jadi keberadaan data anggaran wisata sebelumnya sangat diperlukan pada tahap ini. Percobaan pada penelitian ini akan menggunakan 5 data anggaran biaya wisata sebelumnya. Secara umum struktur sistem pendukung keputusan prediksi anggaran biaya wisata dengan menggunakan metode SAW ditampilkan pada Gambar 2.

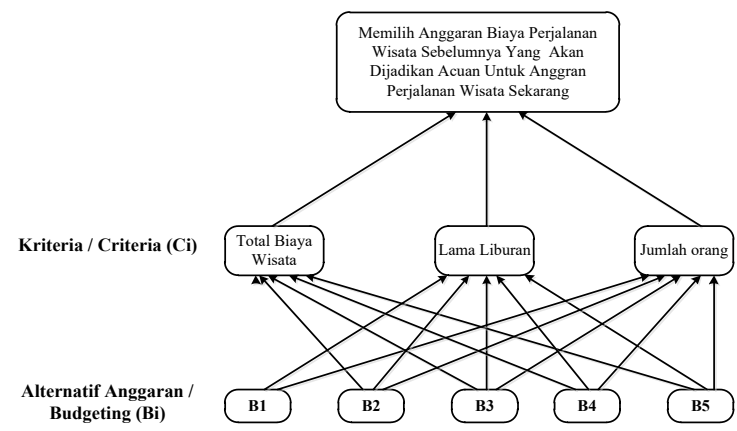

Gambar 2. Struktur Hirarki Alternatif Penentuan Prediksi Anggaran Biaya Wisata

\subsection{Perhitungan Predisksi dengan Metode SAW}

\section{a. Menentukan Kriteria}

Metode SAW mengenal adanya 2 (dua) tipe kriteria yaitu: kriteria keuntungan (benefit) dan kriteria harga (cost). Suatu parameter digolongkan ke dalam kriteria tipe keuntungan (benefit), jika parameter tersebut memiliki nilai yang apabila semakin bertambah maka akan lebih baik (berhubungan dengan topik yang sedang dikaji). Sedangkan suatu parameter digolongkan ke dalam kriteria tipe harga (cost), jika parameter tersebut memiliki nilai yang apabila semakin berkurang maka akan lebih baik (berhubungan dengan topik yang sedang dikaji). Berdasarkan ketentuan tersebut, maka tipe kriteria untuk 3 paremeter yang telah dipilih, sebagai berikut:

1. Total Anggaran Biaya (C1) (tipe : cost)
2. Lama Liburan
(C2) (tipe : benefit)

3. Total Orang

(C3) (tipe : benefit)

\section{b. Menentukan Bobot Masing Kriteria}

Dari setiap kriteria yang sudah ditentukan, kemudian diberi nilai bobot. Nilai bobot setiap kriteria terdiri dari lima kelompok sebagai berikut:
1. Sangat Rendah (SR)
$=0$
2. Rendah (R)
$=0.25$
3. Sedang $(\mathrm{S})$
$=0.5$
4. Tinggi (T)
$=0.75$
5. Sangat Tinggi (ST) 
Tabel 1. Total Anggaran Biaya (C1)

\begin{tabular}{llc}
\hline \multicolumn{1}{c}{ Total Anggaran Biaya } & Keterangan & Nilai \\
\hline Rp. 0- Rp. 500.000 & Sangat Murah & 0 \\
Rp. 500.000-Rp. 1000.000 & Murah & 0,25 \\
Rp. 1.000.000- Rp. 2.000.000 & Sedang & 0,5 \\
Rp. 2.000.000- Rp. 4.000.000 & Mahal & 0,75 \\
Rp. 4.000.000- Rp. 8.000.000 & Sangat Mahal & 1 \\
\hline
\end{tabular}

Tabel 2. Lama Liburan (C2)

\begin{tabular}{llc}
\hline $\begin{array}{c}\text { Lama } \\
\text { Liburan }\end{array}$ & \multicolumn{1}{c}{ Keterangan } & Nilai \\
\hline 1-2 hari & Sangat Sebentar & 0 \\
3-4 hari & Sebentar & 0,25 \\
5-6 hari & Sedang & 0,5 \\
7-8 hari & Lama & 0,75 \\
9-10 hari & Sangat Lama & 1 \\
\hline
\end{tabular}

Tabel 3. Total Orang (C3)

\begin{tabular}{llc}
\hline Total Orang & \multicolumn{1}{c}{ Keterangan } & Nilai \\
\hline 1-2 orang & Sangat Sedikit & 0 \\
3-4 orang & Sedikit & 0,25 \\
5-6 orang & Sedang & 0,5 \\
7-8 orang & Banyak & 0,75 \\
9-10 orang & Sangat Banyak & 1 \\
\hline
\end{tabular}

Tahap berikutnya, melakukan simulasi alternatif pilihan anggaran biaya wisata. Dalam percobaan ini disiapkan 5 data alternatif anggaran biaya wisata seperti terlihat pada Tabel 4.

Tabel 4. Alternatif Anggaran Biaya Wisata Taman Safari

\begin{tabular}{llrrr}
\hline Kode & Anggaran & $\begin{array}{c}\text { Biaya } \\
\text { (juta) }\end{array}$ & $\begin{array}{c}\text { Lama } \\
\text { Liburan } \\
\text { (hari) }\end{array}$ & $\begin{array}{r}\text { Jumlah } \\
\text { Orang }\end{array}$ \\
\hline A1 & $\begin{array}{l}\text { Anggaran Taman } \\
\text { Safari-1 }\end{array}$ & 1,5 & 1 & 5 \\
A2 & $\begin{array}{l}\text { Anggaran Taman } \\
\text { Safari-2 }\end{array}$ & 1 & 5 & 3 \\
A3 & $\begin{array}{l}\text { Anggaran Taman } \\
\text { Safari-3 }\end{array}$ & 1,8 & 2 & 4 \\
A4 & $\begin{array}{l}\text { Anggaran Taman } \\
\text { Safari-4 }\end{array}$ & 3,5 & 7 & 7 \\
\hline A5 & $\begin{array}{l}\text { Anggaran Taman } \\
\text { Safari-5 }\end{array}$ & 7 & 3 & 8 \\
\hline
\end{tabular}

\section{c. Menentukan rating nilai kecocokan setiap alternatif pada setiap kriteria}

Penentuan rating nilai kecocokan dilakukan dengan memasukan nilai dari setiap kriteria ke dalam tabel rating kecocokan yang telah disesuaikan dengan nilai dari tabel kriteria. Hasil pencocokan tersebut ditampilkan pada tabel 5.

Tabel 5. Rating kecocokan kriteria

\begin{tabular}{cccc}
\hline A & & Kriteria & \\
\cline { 2 - 4 } & C1 & C2 & C3 \\
A1 & Sedang & Sangat sebentar & Sedang \\
A2 & Murah & Sedang & Sedikit \\
A3 & Sedang & Sangat sebentar & Sedikit \\
A4 & Mahal & Lama & Banyak \\
A5 & Sangat mahal & Sebentar & Banyak \\
\hline
\end{tabular}

Selanjutnya dibentuk matriks keputusan $\mathrm{x}$ yang dikonversikan ke dalam bilangan fuzzy.

$$
\text { Matrix }=\left(\begin{array}{rrr}
0,5 & 0 & 0,5 \\
0,25 & 0,5 & 0,25 \\
0,5 & 0 & 0,25 \\
0,75 & 0,75 & 0,75 \\
1 & 0,25 & 0,75
\end{array}\right)
$$

\section{d. Normalisasi Matriks}

Berdasarkan matriks rating kecocokan, langkah selanjutnya melakukan normalisasi matriks untuk menghitung nilai masing-masing kriteria berdasarkan kriteria yang diasumsikan sebagai kriteria tipe cost dan benefit. Berikut hasil perhitungan nilai rating kecocokan:

1. Kriteria Total Anggaran Biaya (C1) - cost

$$
\begin{aligned}
& \mathrm{R}_{11}=\frac{\operatorname{Min}(0,5 ; 0,25 ; 0,5 ; 0,75 ; 1)}{0,5}=\frac{0,25}{0,5}=0,5 \\
& \mathrm{R}_{21}=\frac{\operatorname{Min}(0,5 ; 0,25 ; 0,5 ; 0,75 ; 1)}{0,25}=\frac{0,25}{0,25}=1 \\
& \mathrm{R}_{31}=\frac{\operatorname{Min}(0,5 ; 0,25 ; 0,5 ; 0,75 ; 1)}{0,5}=\frac{0,25}{0,5}=0,5 \\
& \mathrm{R}_{41}=\frac{\operatorname{Min}(0,5 ; 0,25 ; 0,5 ; 0,75 ; 1)}{0,75}=\frac{0,25}{0,75}=0,33 \\
& \mathrm{R}_{51}=\frac{\operatorname{Min}(0,5 ; 0,25 ; 0,5 ; 0,75 ; 1)}{1}=\frac{0,25}{1}=0,25
\end{aligned}
$$

2. Kriteria Lama Liburan $(\mathrm{C} 2)$ - benefit

$$
\begin{aligned}
& \mathrm{R}_{12}=\frac{0}{\operatorname{Max}(0 ; 0,5 ; 0 ; 0,75 ; 0,25)}=\frac{0}{0,75}=0 \\
& \mathrm{R}_{22}=\frac{0,5}{\operatorname{Max}(0 ; 0,5 ; 0 ; 0,75 ; 0,25)}=\frac{0,5}{0,75}=0,67 \\
& \mathrm{R}_{32}=\frac{0}{\operatorname{Max}(0 ; 0,5 ; 0 ; 0,75 ; 0,25)}=\frac{0}{0,75}=0 \\
& \mathrm{R}_{42}=\frac{0,75}{\operatorname{Max}(0 ; 0,5 ; 0 ; 0,75 ; 0,25)}=\frac{0,75}{0,75}=1 \\
& \mathrm{R}_{52}=\frac{0,25}{\operatorname{Max}(0 ; 0,5 ; 0 ; 0,75 ; 0,25)}=\frac{0,25}{0,75}=0,33
\end{aligned}
$$

3. Kriteria Total Orang $(\mathrm{C} 3)$ - benefit

$$
\begin{aligned}
& \mathrm{R}_{13}=\frac{0,5}{\operatorname{Max}(0,5 ; 0,25 ; 0,25 ; 0,75 ; 0,75)}=\frac{0,5}{0,75}=0,67 \\
& \mathrm{R}_{23}=\frac{0,25}{\operatorname{Max}(0,5 ; 0,25 ; 0,25 ; 0,75 ; 0,75)}=\frac{0,25}{0,75}=0,33 \\
& \mathrm{R}_{33}=\frac{0,25}{\operatorname{Max}(0,5 ; 0,25 ; 0,25 ; 0,75 ; 0,75)}=\frac{0,25}{0,75}=0,33 \\
& \mathrm{R}_{43}=\frac{0,75}{\operatorname{Max}(0,5 ; 0,25 ; 0,25 ; 0,75 ; 0,75)}=\frac{0,75}{0,75}=1 \\
& \mathrm{R}_{53}=\frac{0,75}{\operatorname{Max}(0,5 ; 0,25 ; 0,25 ; 0,75 ; 0,75)}=\frac{0,75}{0,75}=1
\end{aligned}
$$




Matriks $\quad\left(\begin{array}{ccc}0,5 & 0 & 0,67 \\ 1 & 0,67 & 0,33 \\ 0,5 & 0 & 0,33 \\ & & \\ 0,33 & 1 & 1 \\ 0,25 & 0,33 & 1\end{array}\right)$

\section{e. Perhitungan Rangking Hasil Rekomendasi Alternatif}

Pada tahap ini terdapat proses penjumlahan dari hasil perkalian matriks ternormalisasi dengan nilai bobot. Hasil dari perhitungan tersebut kemudian melakukan perangkingan. Alternatif yang memiliki nilai tertinggi menjadi rekomendasi terbaik dalam menentukan keputusan.

$$
\text { Vektor bobot: } \mathrm{W}=(1 ; 0,5 ; 0,75)
$$

Setelah diperoleh table ternormalisasi, selanjutnya dibuat perkalian matriks $\mathrm{W} \times \mathrm{R}$ :
a. $\mathrm{V}_{1}=(1 \times 0,5)+(0,5 \times 0)+(0,75 \times 0,67)=1,0025$
b. $\mathrm{V}_{2}=(1 \times 1)+(0,5 \times 0,67)+(0,75 \times 0,33)=$ 1,5825
c. $\mathrm{V}_{3}=(1 \times 0,5)+(0,5 \times 0)+(0,75 \times 0,33)=0,7475$
d. $\quad V_{4}=(1 \times 0,33)+(0,5 \times 1)+(0,75 \times 1)=1,58$
e. $V_{5}=(1 \times 0,25)+(0,5 \times 0,33)+(0,75 \times 1)=1,165$

Tabel 6. Perangkingan

\begin{tabular}{ccccc}
\hline A & \multicolumn{3}{c}{ Kriteria } & Hasil \\
\cline { 2 - 4 } & $\mathrm{C} 1$ & $\mathrm{C} 2$ & $\mathrm{C} 3$ & Akhir \\
A1 & 0,5 & 0 & 0,5025 & 1,0025 \\
$\mathrm{~A} 2$ & 1 & 0,335 & 0,2475 & 1,5825 \\
A3 & 0,5 & 0 & 0,2475 & 0,7475 \\
A4 & 0,33 & 0,5 & 0,75 & 1,58 \\
A5 & 0,25 & 0,165 & 0,75 & 1,165 \\
\hline
\end{tabular}

Hasil perhitungan nilai yang lebih besar mengindikasikan bahwa alternatif besar merupakan alternatif terbaik. Hasil dari penilaian terbesar ada pada yaitu A2, sehingga A2 layak atau dapat dijadikan alternatif terbaik.

\subsection{Perancangan Sistem}

Prediksi anggaran biaya wisata selanjutnya akan diimplemantasikan ke dalam aplikasi program berbasis komputer. Aplikasi dirancang untuk dijalankan berbasis web. Secara umum alur jalannya aplikasi ditampilkan pada gambar 2.

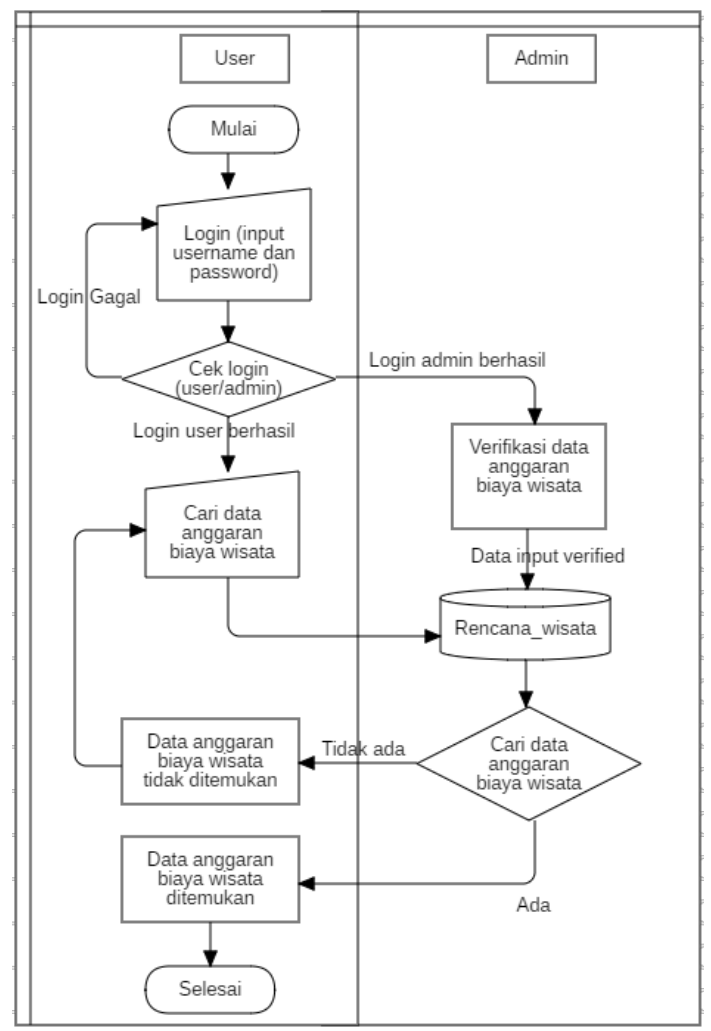

Gambar 2. Diagram Alir Cari Data Anggaran Biaya Wisata

Interaksi dari dua entitas atau aktor utama dalam mengakses setiap proses yang terdapat dalam sistem digambarkan dengan Use Case seperti terlihat pada gambar 3.

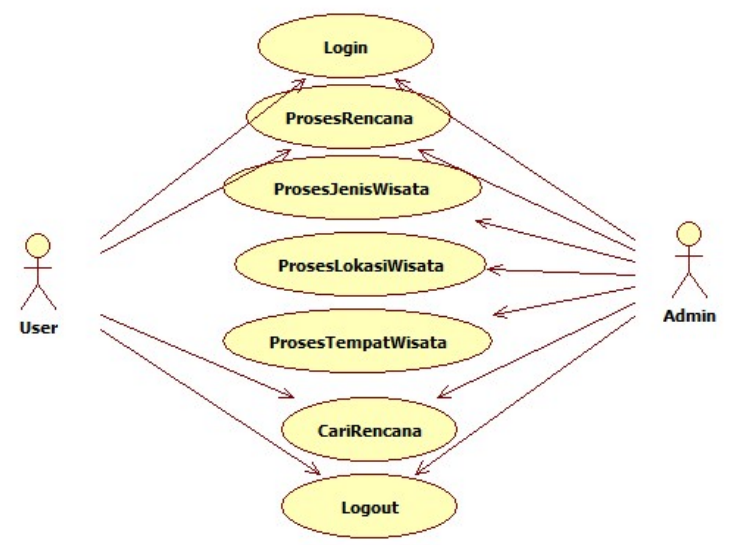

Gambar 3. Use Case Diagram Prediksi Anggaran Biaya Perjalan Wisata

\subsection{Implementasi}

Setelah dilakukan perancangan, tahap berikutnya yaitu implementasi. Pada tahap ini dilakukan coding menggunakan bahasa pemrograman berbasis web. PHP dipilih untuk digunakan sebagai server side scripting yang terkoneksi dengan MySQL database. Apache Web Server diinstal pada Server. Klien dapat mengakses aplikasi dari server melalui web browser seperti Chrome atau Firefox. 


\section{HASIL DAN PEMBAHASAN}

\subsection{Implementasi}

Tahapan pertama pada saat mengakses aplikasi, setelah melakukan login, pengguna dapat melakukan input prediksi rencana anggaran biaya wisata. Beberapa item yang harus diisi oleh pengguna pada tahap ini ditampilkan seperti pada 4.

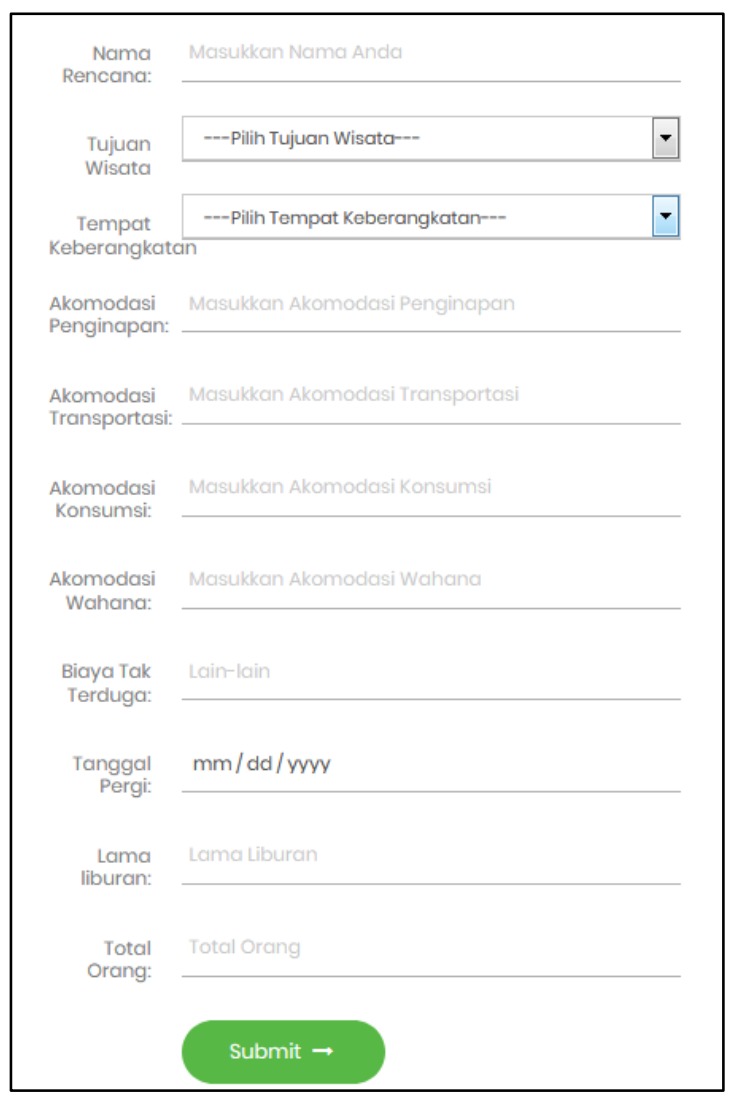

Gambar 5. Halaman Pembuatan

Prediksi Rencana Anggaran Biaya

Setelah input prediksi rencana anggaran biaya selesai dilakukan, tahap berikutnya melakukan pencocokan kesesuaian informasi dengan data rencana anggaran biaya yang telah tersimpan sebelumnya. Tahapan pencarian anggaran biaya sebelumnya ditampilkan seperti pada gambar 6.

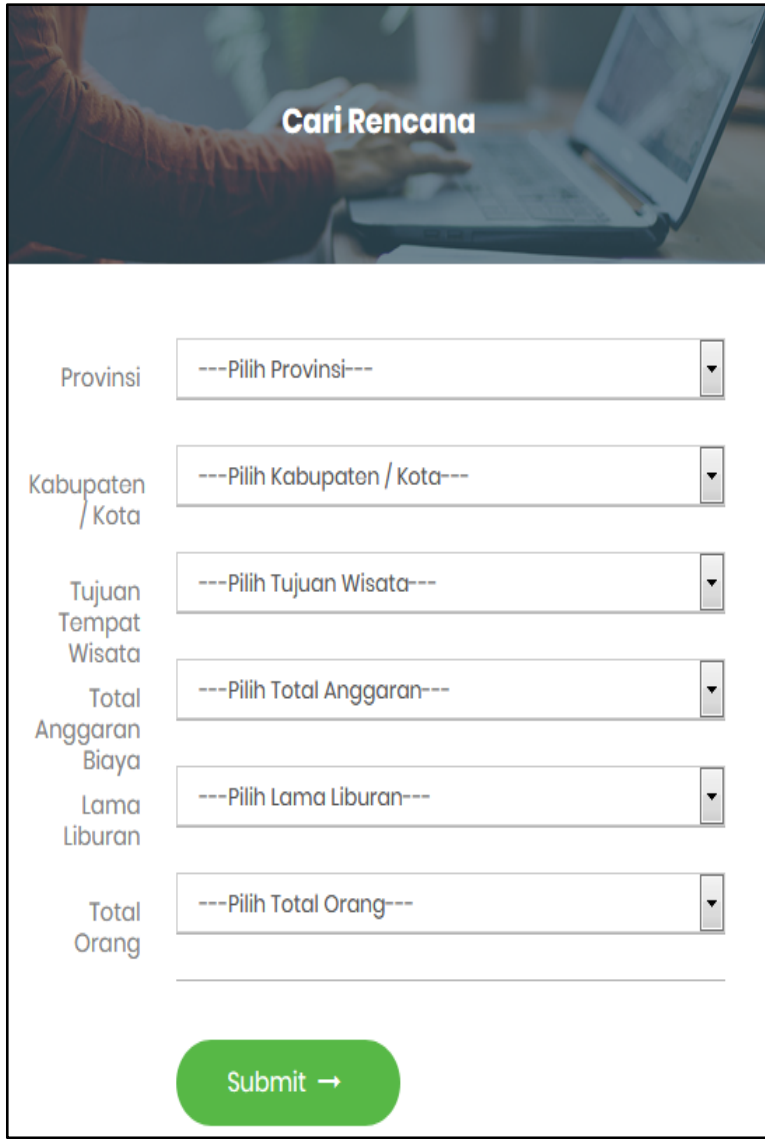

Gambar 6. Halaman Cari Prediksi Anggaran Biaya

Proses pencarian rencana anggaran biaya akan memberikan hasil jika ditemukan data yang cocok. Hasil pencarian data ditampilkan seperti pada gambar 7 .

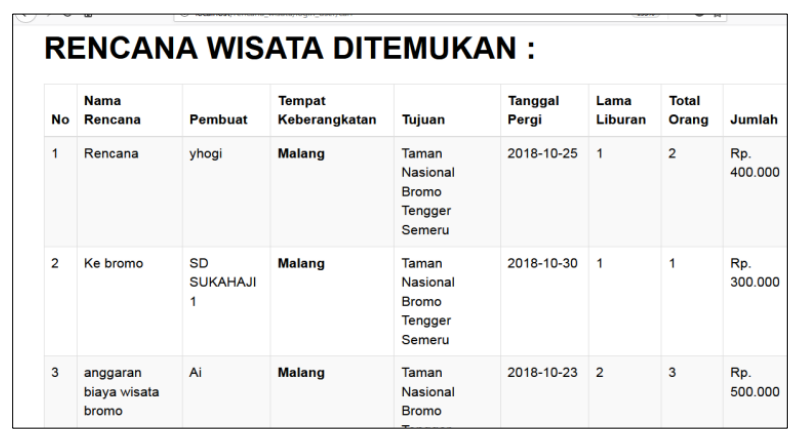

Gambar 7. Halaman Hasil Pencarian

Terdapat beberapa informasi yang ditampilkan hasil dari proses pencarian. Setiap informasi hasil pencarian yang dihasilkan dapat diteluri lebih detail. Detail dari informasi hasil pencarian ditampilan pada gambar 8 .

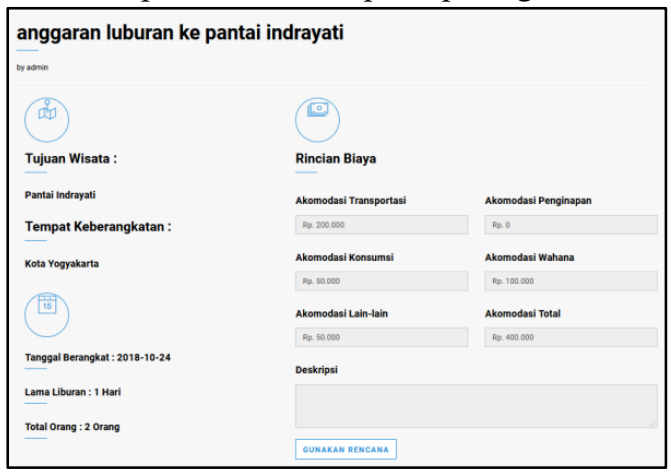

Gambar 8. Halaman Detail Pencarian 
Aplikasi selain dapat diakses oleh pengguna umum dengan hak akses terbatas, juga disediakan hak akses penuh sebagai admin. Informasi prediksi anggaran biaya ketika diakses oleh admin ditampilkan pada gambar 9 .

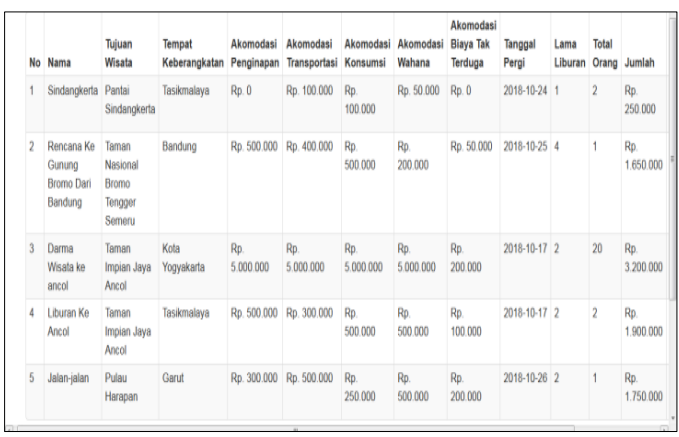

Gambar 9. Halaman Prediksi Anggaran Biaya

Admin juga dapat melakukan verfikasi terhadap semua data yang telah diinput. Halaman verfikasi ditampilkan seperti pada gambar 10 .

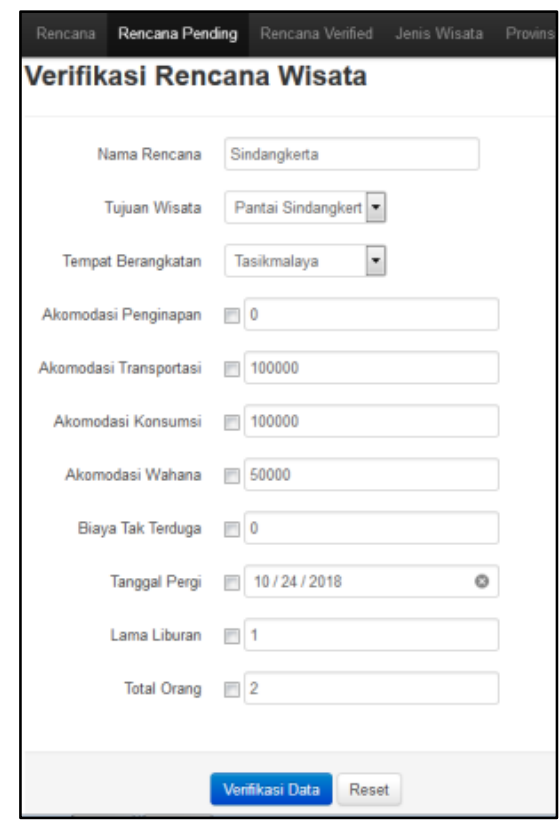

Gambar 10. Halaman Verifikasi Prediksi Anggaran Biaya Perjalan Wisata

\subsection{Pengujian}

\section{a. Pengujian Fungsional}

Pada tahap ini dilakukan pengujian dengan berbagai tipe kasus yang berbeda diantaranya :

1. Input data prediksi anggaran biaya baru

2. Mencari data prediksi anggaran biaya,dengan kasus terdapatsatu data yang mirip pada basis data

3. Mencari data prediksi anggaran biaya,dengan kasus terdapat lebih dari 1 data yang mirip pada basis data

Tabel 6. Pengujian Sistem

\begin{tabular}{lllll}
\hline No & \multicolumn{1}{c}{ Kasus } & \multicolumn{2}{c}{ Deskripsi } & \multicolumn{2}{c}{ Hasil } \\
\hline $\mathbf{1}$ & Input data & Input data & Data & yang \\
& prediksi & prediksi rencana & diinputkan berhasil \\
& baru & dengan data & disimpan ke basis \\
& & yang baru & & data \\
\end{tabular}

\begin{tabular}{|c|c|c|c|}
\hline 2 & $\begin{array}{l}\text { Mencari } \\
\text { data } \\
\text { prediksi } \\
\text { rencana } \\
\text { dengan } 1 \\
\text { data pada } \\
\text { basis data }\end{array}$ & $\begin{array}{l}\text { Melakukan } \\
\text { pencarian } \\
\text { dengan input } \\
\text { yang benar, akan } \\
\text { tetapi data pada } \\
\text { basis data hanya } \\
\text { ada 1 data }\end{array}$ & $\begin{array}{l}\text { Sistem } \\
\text { menampilkan tepat } \\
\text { satu pada hasil } \\
\text { pencarian, karena } \\
\text { terdapat satu record } \\
\text { yang sesuai dengan } \\
\text { data yang diinput }\end{array}$ \\
\hline 3 & $\begin{array}{l}\text { Mencari } \\
\text { data } \\
\text { prediksi } \\
\text { rencana } \\
\text { dengan data } \\
\text { lebih dari } 1 \\
\text { pada basis } \\
\text { data }\end{array}$ & $\begin{array}{l}\text { Melakukan } \\
\text { pencarian } \\
\text { dengan input } \\
\text { yang benar, } \\
\text { dengan data } \\
\text { pada basis data } \\
\text { lebih dari } 1 \text { data }\end{array}$ & $\begin{array}{l}\text { Sistem } \\
\text { menampilkan lebih } \\
\text { dari satu data pada } \\
\text { hasil pencarian, } \\
\text { karena terdapat } \\
\text { lebih satu record } \\
\text { yang sesuai dengan } \\
\text { data yang diinput }\end{array}$ \\
\hline
\end{tabular}

b. Pengujian Perhitungan Pencarian Data

1. Anggaran ke Pulau Harapan 1 (A1)

2. Anggaran ke Pulau Harapan 2 (A2)

3. Anggaran ke Pulau Harapan 3 (A3)

4. Anggaran ke Pulau Harapan 4 (A4)

5. Anggaran ke Pulau Harapan 5 (A5)

Tabel 7. Data alternatif

\begin{tabular}{cccc}
\hline A & \multicolumn{3}{c}{ Kriteria } \\
\cline { 2 - 4 } A1 & C1 & C2 & C3 \\
A2 & Sangat & Sedang & $\begin{array}{l}\text { Sangat } \\
\text { Sedikit }\end{array}$ \\
& mahal & Sedang & Banyak \\
A3 & Murah & $\begin{array}{c}\text { Sangat } \\
\text { sebentar }\end{array}$ & $\begin{array}{l}\text { Sangat } \\
\text { Sedikit }\end{array}$ \\
A4 & Mahal & $\begin{array}{c}\text { Sangat } \\
\text { sebentar }\end{array}$ & $\begin{array}{l}\text { Sangat } \\
\text { Sedikit }\end{array}$ \\
& & Sangat & Sedikit \\
A5 & Sebentar & \\
\hline
\end{tabular}

Tabel 8. Kriteria Pencarian

\begin{tabular}{ll}
\hline & Kriteria Pencarian \\
\hline Pencarian 1 & \\
Total Anggaran & $:$ 2.000.000 - 4.000.000 (Mahal) \\
Lama Liburan & $:$ 2 Hari (Sangat sebentar) \\
Jumlah Orang & $:$ 1 Orang (Sangat sedikit) \\
Pencarian 2 & \\
Total Anggaran & $:$ 1.000.000 - 2.000.000 (Sedang) \\
Lama Liburan & $:$ 2 Hari (Sangat sebentar) \\
Jumlah Orang & $:$ 3 Orang (Sedikit) \\
Pencarian 3 & \\
Total Anggaran & $:$ 2.000.000-4.000.000 (Mahal) \\
Lama Liburan & $:$ 5 Hari (Sedang) \\
Jumlah Orang & $:$ 2 Orang (Sangat sedikit) \\
Pencarian 4 & \\
Total Anggaran & $:$ 500.000 - 1.000.000 (Murah) \\
Lama Liburan & $:$ 1 Hari (Sangat sebentar) \\
Jumlah Orang & $:$ 2 Orang (Sangat sedikit) \\
Pencarian 5 & \\
Total Anggaran & $:$ 4.000.000-8.000.000 \\
Lama Liburan & $:$ (S Hangat Mahal) \\
Jumlah Orang & $:$ 7 Orang (Banyak) \\
\hline
\end{tabular}


Hasil simulasi pencarian data berdasarkan data anggaran yang sesuai dengan data pencarian menghasilkan alternatif pencarian terbaik sebagai berikut : Pencarian 1 hasil alternatif terbaik yaitu Anggaran ke Pulau Harapan 4 (A4), Pencarian 2 hasil alternatif terbaik yaitu Anggaran ke Pulau Harapan 5 (A5), Pencarian 3 hasil alternatif terbaik yaitu Anggaran ke Pulau Harapan 1 (A1), Pencarian 4 hasil alternatif terbaik yaitu Anggaran ke Pulau Harapan 3 (A3) dan Pencarian 5 hasil alternatif terbaik yaitu Anggaran ke Pulau Harapan 2 (A2). Jadi, hasil perhitungan dengan nilai hasil akhir lebih besar mengindikasikan bahwa alternatif tersebut merupakan alternatif terbaik.

\section{KESIMPULAN}

Metode SAW berhasil diterapkan pada prediksi perhitungan anggaran biaya wisata dengan menggunakan 3 parameter : total anggaran biaya, lama liburan dan total orang. Tahapan akhir pada SAW yaitu melakukan perhitungan dengan memberikan nilai rating kecocokan pada setiap kriteria anggaran biaya wisata, kemudian melakukan perhitungan ranking sebagai hasil rekomendasi alternatif. Hasil perhitungan nilai yang paling besar mengindikasikan alternatif terbaik.

Penambahan parameter lainnya dalam perhitungan anggaran biaya wisata, pemilihan tujuan objek wisata yang dihubungkan dengan peta lokasi objek wisata secara online merupakan beberapa tantangan di masa yang akan datang yang dapat dilakukan agar diperoleh hasil prediksi wisata yang lebih akurat.

\section{DAFTAR PUSTAKA}

[1] Chandra, A. A., \& Damarjati, D. (2017, October 17). Detik Finance. Retrieved March 2, 2018, from Detik: https://finance.detik.com/berita-ekonomi-bisnis/d3687715/tiga-tahun-jokowi-jk-pariwisata-sumbangdevisa-terbesar-kedua

[2] Christioko, B. V., Indriyawati, H., \& Hidayati, N. (2017). Fuzzy Multi-Atribute Decision Making (Fuzzy MADM) dengan Metode SAW untuk Pemilihan Mahasiswa Berprestasi. Jurnal Transformaika, 82-85

[3] Dewi, E. K., Suyoto, \& Anindito, K. (2012). ANALISIS DAN PERANCANGAN APLIKASI CASE BASED REASONING UNTUK MENENTUKAN TUJUAN WISATA. Seminar Nasional Informatika 2012, C-33-C-40.

[4] Hardiyanti, T. (2014). SISTEM PENDUKUNG KEPUTUSAN UNTUK MENENTUKAN BIAYA SPP (SUMBANGAN PENYELENGGARAAN PENDIDIKAN) BAGI SISWA BARU DENGAN MENGGUNAKAN METODE SAW (SIMPLE ADDITIVE WEIGHTING) PADA SMK St. FRANSISKUS SEMARANG. Jurnal Universitas Dian Nuswantoro.

[5] Hendra, Tursina, \& Nyoto, R. D. (2017). Case Base Reasoning Penentuan Harga Rumah Dengan Menggunakan Metode Tversky (Studi Kasus: Kota Pontianak). Jurnal Sistem dan Teknologi Informasi, $1-5$.

[6] Ikmah, \& Widawati, S. A. (2018). Sistem Pendukung Keputusan Pemilihan Tempat Wisata Purworejo
Menggunakan Metode SAW. Seminar Nasional Teknologi Informasi dan Multimedia 2018, 91-96.

[7] Kosasi, S. (2013). SISTEM PENUNJANG KEPUTUSAN MEMILIH PAKET WISATA DENGAN METODE CASE-BASED REASONING. JURNAL SISFOTENIKA, Vol. 3 No. 2, 81-89.

[8] Nugroho, S. (2014). SISTEM PENDUKUNG KEPUTUSAN PEMILIHAN LOKASI OBJEK WISATA DI KABUPATEN GROBOGAN MENGGUNAKAN METODE PROFILE MATCHING. Jurnal Universitas Dian Nuswantoro.

[9] Prasetya, I., \& Rahayu, Y. (2015). PENENTUAN HARGA JUAL SEPEDA MOTOR BEKAS MENGGUNAKAN FUZZY LOGIC (METODE TSUKAMOTO). Jurnal Universitas Dian Nuswantoro, 1-8.

[10] Riadi, M. (2013). Sistem Pendukung Keputusan (SPK). Retrieved Juli 6, 2018, from http://ww.kajianpustaka.com/2013/09/sisteempendukung-keputusan-spk.html

[11] Saltuk, O., \& Kosan, I. (2014, Mei 7). Design \& Creation. Ludwig Maximilians Universitat Munchen.

[12] Sasmita, M. D. (2014). Extreme Programming sebegai metode pengembangan sistem. Paper Ilmiah, Unviseritas Bina Nusantara.

[13] Sopian, S. (2017, January 17). Men Scope. Retrieved March 2, 2018, from Male Indonesia: https://male.co.id/detail/1921/PentingnyaPerencanaan-Budget-untuk-Berlibur-Men-Scope

[14] Suryanto, E., Honggowibowo, A. S., \& Retnowati, N. D. $(2013$, Mei). SISTEM PENDUKUNG KEPUTUSAN OTOMATISASI PLANNING WISATA BERBASIS WEBSITE DENGAN MENGGUNAKAN METODE DIJKSTRA. Compiler, Volume 2, Nomor 1.

[15] Sutoyo, M. N., \& Sumpala, A. T. (2017). CASE BASED REASONING MENENTUKAN KELOMPOK UKT (STUDI UNIVERSITAS SEMBILANBELAS NOVEMBER KOLAKA). Seminar Nasional Matematika dan Aplikasinya, 401407.

[16] Tanjung, D. H. (2013). PEMILIHAN OBJEK WISATA DI SUMATERA UTARA DENGAN METODE ANALYTICAL HIERARCHY PROCESS (AHP). Seminar Nasional Informatika 2015, 592-597.

[17] Zain, N., Michrandi, S., \& Novianty, A. (2015). SISTEM PENDUKUNG KEPUTUSAN UNTUK MENENTUKAN BESARAN ORDER MENGGUNAKAN ALGORITMA FUZZY DALAM TOKO PINTAR TANPA KASIR. eProceeding of Engineering, 1-10. 


\section{BIODATA PENULIS}

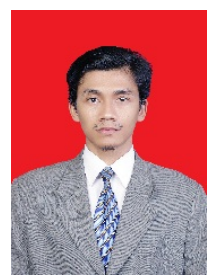

Yhogi Andianggara

Mahasiswa Jurusan Informatika

Fakulats Teknik Universitas

Siliwangi.

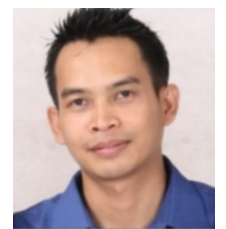

Rohmat Gunawan, ST., MT Dosen Teknik Informatika, Fakultas Teknik, Universitas Siliwangi. Konsentrasi riset pada bidang: Jaringan Komputer, Sistem Terdistribusi, Keamanan Komputer.

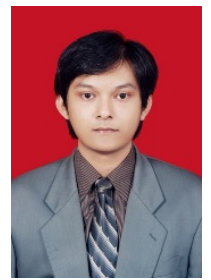

Aldy Putra Aldya, ST., MT Dosen Teknik Informatika, Fakultas Teknik, Universitas Siliwangi. Konsentrasi riset pada bidang Pengolahan Citra, Multimedia dan Game, dan Grafika Komputer 